\title{
A análise da (in)aplicabilidade da lei maria da penha aos casos de mulheres transexuais e travestis em situação de violência doméstica e familiar
}

The analysis of (in)applicability of the Maria da Penha law to the cases of transexual women and travestis in the situation of domestic and Family violence

RESUMO

Sustentada como resquício do modelo de família patriarcal, a violência doméstica foi responsável pela triste e persistente luta de Maria da Penha Maia Fernandes contra o Estado brasileiro, buscando por justiça. Em 2006 , finalmente, entrou em vigor a Lei 11.340, conferindo proteção ao gênero socialmente vulnerável, o feminino.

PALAVRAS-CHAVE: Violência Doméstica. Gênero. Transgênero. Travesti.

\begin{abstract}
Sustained as a remnant of the model of patriarchal family, domestic violence was responsible for the sad and persistent struggle of Maria da Penha Maia Fernandes against the Brazilian State, searching for justice. In 2006, finally entered into force the Law 11.340, giving protection to the genus socially vulnerable, the feminine.

KEYWORDS: Domestic Violence. Gender. Transgender. Transvestite.
\end{abstract}

A problemática abordada no presente estudo nasce a partir do elemento violência doméstica e familiar, que se sustenta na cultura brasileira como resquícios do modelo de família patriarcal. Neste modelo, a família, composta por um homem e uma mulher e filhos, quando houver, é liderada pela figura masculina, enquanto a figura feminina é transportada

\footnotetext{
${ }^{1}$ Pós-graduado lato sensu em Direito Penal e Processual Penal (2018). Graduado em Direito - Centro Universitário São Camilo - Espírito Santo (2017). Advogado. E-mail: eltonsampaio@outlook.com.br.

2 Doutoranda no programa de Pós-graduação strictu sensu em Direitos e Garantias Fundamentais FDV/ES (2015). Mestre em Políticas Públicas e Processo - UNIFLU RJ 92007). Especialista em Direito Processual Civil - FDV/ES (2004). Graduada em Direito - FDI/ES (2000). Professora do Centro Universitário São Camilo - Espírito Santo. E-mai: tmareto@gmail.com.
} 
para uma posição inferior, de delicadeza, ineficiência e responsável por afazeres domésticos.

O íntimo e privado ambiente doméstico possui as condições ideais para que o homem tenha a falsa percepção de poder e propriedade sobre sua família, em especial a esposa, deixando־o bastante à vontade para a prática de diferentes atos de diversas formas de violência, da física à psicológica. Porém, a privacidade doméstica não justifica a omissão do Estado diante de atos violentos.

Com repercussão internacional, o caso Maria da Penha Maia Fernandes trouxe importantes mudanças no Ordenamento Jurídico nacional, denunciando a precariedade e o desinteresse do Estado brasileiro apurar os casos de violência doméstica e familiar contra a mulher. Depois de sofrer diversas agressões, Maria da Penha buscou o Judiciário por justiça, mas o processo ficou em trâmite por mais de quinze anos sem uma resposta efetiva.

Em razão da ausência de resposta adequada ao caso levado ao Judiciário brasileiro, a Organização dos Estados Americanos - OEA foi peticionada, denunciando a violação de tratados de Direitos Humanos pelo Estado brasileiro, os quais o país é signatário, resultando em condenação do Estado brasileiro.

A condenação recomendou a criação de mecanismos para o combate à violência doméstica, dispondo, também, de ferramentas processuais efetivas para a tutela de casos que envolvessem violência doméstica e familiar contra mulheres. O resultado da condenação foi a criação da Lei 11.340/2006, chamada de "Lei Maria da Penha" em homenagem à vítima Maria da Penha Maia Fernandes. 
Surgiu, então, uma importante ferramenta legislativa para o combate à violência doméstica e familiar contra a mulher. E, neste passo, o segundo pilar da problemática trabalhada no presente estudo, relacionada à interpretação da expressão "mulher".

$\mathrm{O}$ artigo tem o escopo de demonstrar a possibilidade de aplicação da expressão "mulher" em situações distintas: A primeira faz referência ao conceito binário de "homem/mulher", considerando tão somente o sexo biológico, algo equivalente à classificação "macho/fêmea" humana; a segunda situação faz referência à classificação em razão da identidade de gênero, trazendo a figura da mulher cisgênero e da mulher transgênero. A abordagem de sexo biologicamente designado e identidade de gênero serão expostas pormenorizadas em capítulo próprio, por ora, o fundamental é demonstrar o objetivo do presente artigo.

Diante do amplo conceito da expressão "mulher" estampada na Lei 11.340/2006, surgiu a problemática trabalhada ao longo deste estudo, o qual analisa a (in)aplicabilidade dessa importante ferramenta legislativa aos casos em que as vítimas são mulheres transexuais e travestis, que vivenciam papéis femininos em seus cotidianos.

Flagrante incompatibilidade com o Estado Democrático de Direito permitir que o próprio operador de direito, baseando-se em critérios puramente pessoais, determine se a vítima transmulher ou travesti deve, ou não, ser considerada mulher, ao buscar tutela estatal. A certeza é que essas mulheres se tornam duplamente vítimas: (i) Das agressões por parte de seus familiares e companheiros; (ii) e do próprio Estado, que deixa de reconhecer a feminilidade dessas mulheres, não aplicando a ferramenta correta para coibir e combater a violência doméstica, perpetuando, através de sua ineficácia, a cultura de enxergar a violência doméstica como algo absolutamente normal. 
Assim, o presente estudo se desenvolveu a partir do seguinte questionamento: Quais seriam os contornos teóricos e normativos que sustentariam, ou não, a aplicabilidade da Lei Mara da Penha às vítimas transmulheres e travestis, uma vez que o texto legal utiliza apenas a expressão "mulher"?

O estudo foi desenvolvido através do método dialético idealista hegeliano, munindo-se da tese de que a Lei Maria da Penha confere proteção à mulher, propondo a antítese de que as transmulheres e as travestis, vivenciando os papéis femininos em seus cotidianos, também devessem ser protegidas por esta Lei, alcançando a síntese de que a referida Lei deveria, ou não, ser aplicada aos casos em que as transmulheres e as travestis estivessem na situação da violência em que a Lei Maria da Penha visa coibir.

Depois de explícita a base lógica, em que foi eleito o método dialético, o presente estudo definiu a técnica de investigação. Inicialmente, foi aplicada a técnica comparativa para examinar o projeto que originou a Lei 11.340/2006, permitindo identificar a intenção do legislador ao editar a Lei Maria da Penha. Após a verificação da intenção do legislador, o estudo analisou o contexto da violência abordada pela Lei Maria da Penha, objetivando identificar a possível existência de vulnerabilidade à violência do gênero feminino. Para não prejudicar a técnica investigativa, este estudo instruiu o seu desenvolvimento com a distinção entre sexo biologicamente designado, identidade de gênero e sexualidade, trabalhando de forma específica para a definição das figuras das transmulheres e das travestis.

Para alcançar uma conclusão segura, o estudo aplicou a técnica estatística em conjunto com a técnica comparativa. As estatísticas trazidas ao estudo objetivam demonstrar a existência de vulnerabilidade à violência doméstica e familiar em que o gênero feminino permanece exposto em seus lares, reforçando as conclusões obtidas em sede de técnica comparativa. 
Trazidas as definições acerca do sexo biológico e identidade de gênero, o estudo verifica, através dos métodos e técnicas adotas, se a Lei 11.340/2006 confere proteção às vítimas de violência doméstica e familiar em razão do sexo biologicamente designado ou em razão do gênero feminino. Assim, na hipótese de a Lei 11.340/2006 conferir proteção ao gênero feminino, as ferramentas de combate à violência doméstica e familiar positivadas pela Lei Maria da Penha seriam aplicáveis às vítimas que vivenciam papéis femininos, incluindo as travestis e as transexuais. Caso contrário, a Lei Maria da Penha não seria aplicável aos casos em que a vítima da violência doméstica e familiar não se enquadrasse no grupo de "fêmeas", ainda que assumissem a feminilidade em seu cotidiano.

\section{Violência e relações doméstica e familiar}

Entender o significado da expressão "violência" é fundamental para criar a primeira ideia do objeto deste estudo. $\mathrm{O}$ uso da etimologia, neste caso, servirá de suporte para entender o cenário da violência. Para Stela Soares de Farias Cavalcanti (2010, p. 29), "a etimologia da palavra violência [...] traz [...] as ideias de excesso e de desmedida".

A mesma expressão foi caracterizada pela Organização Mundial de Saúde - OMS, conforme mencionado por Krug et al. (2017, p. 5), o relatório mundial sobre violência e saúde traz a seguinte definição para a palavra "violência":

O uso intencional da força física ou do poder, real ou em ameaça, contra si próprio, contra outra pessoa, ou contra um grupo ou uma comunidade, que resulte ou tenha grande possibilidade de resultar em lesão, morte, dano psicológico, deficiência de desenvolvimento ou privação. 
Ainda mencionado por Krug et al. (2017 p. 6), o mesmo relatório da OMS traz a tipologia da violência, podendo ser "[...] dirigida a si mesmo (auto infligida); violência interpessoal; violência coletiva”.

Atos de violência praticados contra o próprio agressor, incluindo suicídios e automutilação, são definidos, conforme Krug et al. (2017, p. 6), como a violência contra si mesmo. Não há, portanto, a figura de um terceiro agressor, agindo com excessos e desmedidas. O segundo grupo versa sobre a violência coletiva, compreendendo os atos violentos por grupos que se assemelham, compartilhando, por exemplo, a mesma ideologia política. O terceiro e último grupo abordou a violência interpessoal. Neste grupo, são englobados os atos ocorridos entre as pessoas em sua individualidade, subdividindo-se em violência comunitária ou violência da família e de parceiro íntimo.

O presente estudo pinçou o subgrupo da violência da família e de parceiro íntimo para desenvolver a problemática da violência no contexto doméstico. Este subgrupo faz referência à violência ocorrida no ambiente familiar, independentemente da modalidade e da forma como se manifesta, incluindo a verbal, sexual, patrimonial, moral..., bastando que o ato violento seja praticado dentro do contexto doméstico, familiar ou dentro de relação íntima de afeto.

Considerando a abordagem do presente estudo, é importante salientar que para a Lei 11.340 (BRASIL, 2006), a unidade doméstica é o espaço onde determinadas pessoas convivem, em regra, de forma permanente. A exceção ocorre quando o membro desse ambiente possui outra unidade doméstica concomitante, ou se torne temporariamente agregado. Não há, portanto, a exigência de vínculo familiar, podendo ser constituída a partir de pessoas aleatórias que passam a compartilhar permanentemente uma mesma residência. 
A expressão "contexto familiar" faz referência ao conjunto intrafamiliar, bem como aos demais familiares. Da mesma forma, a Lei 11.340 (BRASIL, 2006) considera unidade familiar, o grupo de pessoas que são ou se consideram família. Incluem-se, neste grupo, as relações parentescas em razão de laços sanguíneos, laços afetivos, laços de afinidade e relações aparentadas por manifesta vontade. Nesse sentido, Alice Bianchini (2016) elenca os formatos do contexto familiar, podendo existir através do vínculo natural, sendo o pai, a mãe, o irmão, a irmã, etc.; vínculo civil, como ocorre com a relação entre sogra e nora/genro, cunhados, marido/esposa, etc.; vínculo por afinidade, no caso de relação entre primos, tios, etc.; e vínculo afetivo, quando o contexto familiar é formado por amigos que moram num mesmo apartamento, por exemplo.

Por sua vez, a "relação íntima de afeto" faz referência aos relacionamentos que existem ou já existiram. Tem o escopo de estender o conceito às relações de ex-cônjuges. Nesse sentido, relação íntima de afeto independe da existência de coabitação, conforme ideia estampada na Lei 11.340 (BRASIL, 2006). Independentemente, inclusive, da existência de relação amorosa/sexual, ou seja, não se pode associar a expressão "íntima de afeto" com a prática sexual.

\subsection{Relação entre violência e cultura brasileira}

Cultura são os "modos de vida que caracterizam uma coletividade" (CANEDO, 2009). No Brasil, a cultura é marcada pela forma de vida desproporcional e desigual no aspecto econômico, intelectual, de oportunidades de desenvolvimento..., gerando violência de diversas formas. O grave problema de a violência fazer parte da cultura, é que ela passa a ser encarada de forma normal, natural, agregando-se ao senso comum. 
Com relação ao senso comum, Stela Valéria Soares de Farias Cavalcanti cita Marilena Chauí, explicando:

O senso comum é um conjunto de crenças, valores, saberes e atitudes que a sociedade julga naturais porque transmitidos de geração a geração, sem questionamentos. Em algum momento da vida foi dito como são e o que valem as coisas e os seres humanos, como devem ser avaliados e tratados e nós aceitamos estas informações sem contestação. (CAVALCANTI, 2010, p. 31).

O senso comum, neste estudo, está intrinsecamente conexo ao senso de que o homem ocupa o topo da organização social, estando, a mulher, alocada abaixo, ocupando uma figura de submissão em relação àquele do topo.

Obviamente, em tempos remotos, esse modelo social/organizacional era exacerbadamente manifesto. Isso ocorre porque, ao longo de diversas gerações, as famílias se organizavam de acordo com o modelo patriarcal.

No modelo de organização patriarcal, há um chefe do sexo masculino, casado com uma mulher que vive em função do seu marido, satisfaz as vontades do chefe da família, ainda que contra suas próprias vontades. Marta Giudice Narvaz (2005) trata a organização patriarcal como uma "ideologia a qual interessa manter as mulheres em uma posição de dominação".

Porém, o modelo patriarcal se tornou incompatível com o texto da Constituição Federal da República do Brasil de 1988, ao expressar em seu artigo $5^{\circ}$, I, que "homens e mulheres são iguais em direitos e obrigações [...]" (BRASIL, 1988).

Ainda há muitas problemáticas contornando esse tratamento igualitário trazido pela Constituição Federal de 1988, pois culturalmente há uma forte tendência em atribuir papéis sociais de acordo com o sexo, criando um conjunto de atividades típicas masculinas versus femininas, das mais 
simples às mais complexas, da divisão de cores masculinas e femininas até a liberdade da manifestação sexual.

\section{Lei maria da penha: do caso concreto à criação da lei 11.340 de 07 de agosto de 2006}

Batizada como "Lei Maria da Penha - LMP", a Lei 11.340/2006 foi criada por força de condenação internacional, resultado de caso concreto levado à Corte Interamericana de Direitos Humanos - CIDH, em 1988, pela vítima Maria da Penha Maia Fernandes, juntamente com as ONGs Centro pela Justiça e o Direito Internacional - $\mathrm{CEJIL}^{3}$ e Comitê da América Latina e o Caribe para a Defesa dos Direitos da Mulher - CLADEM, após a excessiva demora do Judiciário brasileiro em entregar a tutela estatal em caso concreto específico de violência doméstica.

Maria da Penha conheceu Marco Antônio Heredia Viveros durante a vida acadêmica, com quem se casou em 1976. Do relacionamento, o casal teve duas filhas. Na constância do casamento, Maria da Penha foi submetida a diversos ciclos de violência doméstica de diferentes formas. Cansada do relacionamento angustiante, Maria da Penha manifestou seu desejo de separação, o que foi negado por Marco Antônio. Em 29 de maio de 1983, Marco decidiu atentar contra a vida de sua esposa, disparando um tiro, atingindo a coluna de Maria da Penha, ocasionando a paraplegia dos membros inferiores. Maria da Penha foi socorrida e permaneceu quatro meses hospitalizada. Ao retornar para casa, Marco tentou eletrocutá-la, entretanto, o objetivo de matar Maria da Penha não foi alcançado. Somente após a segunda tentativa de homicídio, a vítima conseguiu a separação de corpos, quando, enfim, pode sair do próprio lar, levando suas filhas. (TEDXFORTALEZA, 2012).

\footnotetext{
${ }^{3}$ Center for Justice and International Law - CEJIL. 
Denunciado, Marco respondeu ao processo penal, mas permaneceu em liberdade após a condenação de primeira e segunda instância. Transcorridos mais de quinze anos da data dos fatos, o agressor ainda permanecia em liberdade e o Judiciário brasileiro não prestava a tutela de forma efetiva e necessária para o devido processamento e condenação do agressor, revelando um padrão de omissão e negligência do Estado em casos de violência doméstica e familiar contra mulheres, razão pela qual Maria da Penha, juntamente com as ONGs CEJIL e CLADEM acionaram a Comissão Internacional de Direitos Humanos - CIDH da Organização dos Estados Americanos - OEA, contra o Estado brasileiro (CNPG, 2011, p. 12).

\subsection{A condenação do Estado brasileiro}

Apesar de não esgotados os recursos da jurisdição do Estado brasileiro, este requisito foi afastado para o recebimento do caso pela CIDH, em razão da "[...] demora injustificada na decisão sobre os mencionados recursos" (OEA, 1969).

O bojo da denúncia sustentou que a demora do Estado brasileiro em processar e julgar o caso de Maria da Penha refletia a tolerância do Brasil para com a violência cometida pelo agressor da vítima, uma vez que já havia transcorrido um prazo excessivo desde a data dos fatos, mais de quinze anos, sem que o caso tivesse uma resposta estatal efetiva e proporcional aos atos violentos.

Depois do regular trâmite e da ausência de manifestação do Estado brasileiro nos autos do processo, a Comissão passou a relatar o caso Maria da Penha. No tocante ao mérito, inicialmente, restou o entendimento que os tribunais brasileiros não entregaram uma tutela eficaz ao caso ora analisado, violando o direito à justiça, às garantias judiciais e à proteção judicial, conforme estabelecido na Convenção Americana de Direitos Humanos (CIDH, 2001, p. 9). 
A forma desigual de tutelar as mulheres foi constatada através de Relatório Especial sobre o Brasil (CIDH, 2001, p. 10):

[...] havia uma clara discriminação contra as mulheres agredidas, pela ineficácia dos sistemas judiciais brasileiros e sua inadequada aplicação dos preceitos nacionais e internacionais, inclusive dos precedentes da jurisprudência da Corte Suprema do Brasil.

Demonstra, no mérito, também, que outros relatórios acerca da violência doméstica no Brasil, concluíam que o Estado não entregava uma resposta eficaz. Nesse sentido, foi o Relatório da Universidade Católica de São Paulo, referente ao levantamento realizado em 1998 (CIDH, 2001, p.10):

[...] 70\% das denúncias criminais referentes à violência doméstica contra mulheres são suspensas sem que cheguem a uma conclusão. Somente $2 \%$ das denúncias criminais de violência doméstica contra mulheres chegam à condenação do agressor.

Apesar de a Comissão se encontrar diante de um caso concreto, a CIDH considerou que a tese sustentada pela parte demandante, não narrava uma situação isolada. Na verdade, a omissão do Estado diante da violência doméstica contra a mulher, refletia um padrão de como o Estado brasileiro tratava os casos envolvendo violência doméstica e familiar.

Nesse sentido, a Comissão recomendou que o Estado brasileiro adotasse medidas para acolher as mulheres vítimas de violência doméstica, bem como dispor de mecanismos legislativos e judiciais para tutelar esses casos, não permanecendo omisso de modo a tolerar a violência doméstica, como se fosse algo absolutamente normal e tolerável.

\subsection{O projeto, a justificativa e a criação da Lei 11.340/2006}

Embora as recomendações da Comissão Interamericana de Direitos Humanos - CIDH tenham sido publicadas 13 de março de 2001, o 
Estado brasileiro permaneceu inerte por mais de três anos, sem qualquer solução.

Somente no dia 24 de novembro de 2004, o Poder Executivo encaminhou projeto de lei ao Congresso Nacional para a criação de mecanismos para coibir a violência doméstica e familiar contra a mulher.

Ao longo do projeto desenvolvido pelo Grupo de Trabalho Interministerial, são apresentadas as justificativas para a pretensão da lei, oportunidade em que são destacadas a necessidade e a importância da matéria tratada. No tópico seguinte, serão extraídas as justificativas que dialogam com o presente estudo.

O Grupo de Trabalho Interministerial - GTI, ao longo da fundamentação do projeto, demonstrou a vulnerabilidade à violência pela mulher, através de comparação entre os dados acerca de violência doméstica levantados ao final da década de 1980 e os dados levantados em pesquisa realizada no ano de 2001.

O GTI, autor do projeto de lei 4.559 (BRASIL, 2004), constou que, ao final de 1980, conforme Pesquisa Nacional de Amostra Domiciliar - PNAD realizada pelo Instituto Brasileiro de Geografia e Estatística - IBGE, "63\% das agressões físicas contra as mulheres acontecem nos espaços domésticos e são praticadas por pessoas com relações pessoais e afetivas com as vítimas", revelando que o primeiro atentado contra Maria da Penha, em 1983, era uma mera repetição do costume brasileiro.

Outra pesquisa transportada para o referido projeto, objetivando embasar a proposta legislativa foi realizada pela Fundação Perseu Abramo (2001), através do Núcleo de Opinião Pública, concluindo que “[...] projeta-se cerca de, no mínimo, 2,1 milhões de mulheres espancadas por ano no país (ou em 2001, pois não se sabe se estariam aumentando ou diminuindo), 175 mil/mês, 5,8 $\mathrm{mil} /$ dia, 243/hora ou 4/minuto - uma a cada 15 segundos", 
ratificando as constatações acerca da cultura brasileira de violência doméstica.

Percebeu-se, neste passo, que a proposição de uma lei específica para tutelar as mulheres vítimas de violência doméstica, visava muito além da proteção física das mulheres. $\mathrm{Na}$ verdade, tratava-se de proteção à própria dignidade delas e, ainda mais, era o reflexo da manutenção de verdadeiro estado democrático de direito, em que todos receberiam a proteção estatal necessária, desenvolvendo políticas para a correção de desigualdades nutridas pela própria sociedade.

Aprovado na Câmara dos Deputados, o projeto seguiu para o Senado Federal, onde foi aprovado em plenário e remetido à sanção da Presidência da República em 19 de julho de 2006, sendo, o Decreto do Congresso Nacional, sancionado e transformado na Lei 11.340/2006, sem qualquer veto presidencial.

A problemática do presente estudo reside na possibilidade de mulheres transexuais e travestis se tornarem vítimas da violência no mesmo cenário tutelado pela Lei 11.340/2006. Para o melhor desenvolvimento deste trabalho, o capítulo seguinte tratará da distinção entre sexo e identidade de gênero, verificando, em sede de conclusão, se a LMP seria, ou não, aplicável aos casos envolvendo as referidas vítimas.

\section{Diferenciando sexo biológico, identidade de gênero e sexualidade}

É comum que os termos "sexo", “identidade de gênero" e "sexualidade" sejam empregados de forma equivocada e, por vezes, utilizados erroneamente como sinônimos. Cada uma dessas expressões é conceituada de forma a permitir o diálogo entre si, entretanto, são independentes e não possuem um padrão específico e lógico para que se deduzam onde os sujeitos se enquadram. A seguir, as diferenças serão expostas com o escopo de distinguir cada conceito, trazendo suas 
peculiaridades, demonstrando onde as figuras "transexual" e "travesti" estão alocadas.

\subsection{Sexo biologicamente designado}

O sexo biologicamente designado, também chamado de sexo biológico, sexo designado ou, simplesmente, sexo, é aquele definido pelas características físicas e biológicas do indivíduo. Conforme conceitua Jaqueline Gomes de Jesus (2012, p. 24), o sexo é baseado “[...] em características orgânicas como cromossomos, níveis hormonais, órgãos reprodutivos e genitais [...]”.

A designação do sexo é feita com base, apenas, nas características fisiológicas do ser humano, justamente por isso o emprego da expressão "designar", definida no minidicionário de língua portuguesa, o miniaurélio, como “[...] fixar, marcar." (FERREIRA, p. 244), razão pela qual é possível que um indivíduo tenha seu sexo biológico determinado desde o ato do seu nascimento.

Trata-se, portanto, de um “conjunto de informações cromossômicas, órgãos genitais, capacidades reprodutivas e características fisiológicas secundárias que

distinguem

machos e fêmeas" (ABGLT, 2011, p. 09).

\subsection{Identidade de gênero}

Diferente do sexo biológico designado, a identidade de gênero não é determinada pelos aspectos da formação biológica do indivíduo. Nesse sentido, Jaqueline Gomes de Jesus (2012, p. 8) defende que:

Sexo é biológico, gênero é social, construído pelas diferentes culturas. $\mathrm{E}$ o gênero vai além do sexo: $\mathrm{O}$ que importa, na definição do que é ser homem ou mulher, não são os cromossomos ou a conformação genital, mas 
a auto-percepção e a forma como a pessoa se expressa socialmente.

Ao afirmar que o gênero vai além do sexo, entende-se que há um rompimento no formato padrão dualista de gênero que considerava o sexo biológico como fator vinculado para a identidade de gênero do indivíduo. Nessa visão binária e vinculada, o gênero seria uma extensão do sexo biológico, em que a genitália masculina determinaria o gênero masculino, enquanto a genitália feminina determinaria o gênero feminino, apenas.

\subsubsection{Transexual}

A figura da transexualidade faz referência ao indivíduo que se identifica com um gênero diferente do sexo biologicamente designado, surgindo, a partir daqui as expressões "transmulher" e "transhomem", fazendo referência à mulher que nasceu em corpo masculino, chamada de mulher transexual; e ao homem que nasceu em corpo feminino, chamado de homem transexual, respectivamente. A transexualidade independe da efetiva realização do procedimento cirúrgico de transgenitalização, também chamado de redesignação sexual, porém, há um desejo de reconstruir o corpo através da intervenção cirúrgica.

A mulher transexual enxerga o órgão sexual designado "como um apêndice, portanto, algo que deve ser retirado. Assim, a transexual é aquela que fez (ou deseja fazer) a cirurgia de transgenitalização" (JAYME, 2010, p. 171). Assim, percebe-se que, na transexualidade, há uma incompatibilidade

entre o sexo biológico e a identidade de gênero, fazendo com que o indivíduo queira ajustar seu corpo de acordo com sua identidade de gênero, independentemente da realização do procedimento cirúrgico.

\subsubsection{Travesti}


Assim como as transexuais, as travestis também assumem a identidade de gênero feminina num corpo biologicamente masculino. Entretanto, diferente das transexuais, as travestis não manifestam o desejo de transgenitalização.

Para as travestis, a expressão da feminilidade não está relacionada com o desejo de readequação do corpo, bastando as intervenções "[...] por meio de roupas, maquiagem, cabelo e trejeitos femininos e por meio de medicamentos (hormônios femininos) e silicone em partes do corpo" (JAYME, 2010, p. 169), não causando incômodo a existência de uma genitália masculina.

Ao falar de identidade de gênero, não é raro o emprego de diversos termos como se sinônimos fossem. Para desconstruir essas aplicações equivocadas, foi delineada a figura da transexualidade e a figura da travestilidade, demonstrando que não se trata de sinônimos, trata-se, na verdade, de grupos distintos que vivenciam a feminilidade todos os dias. Porém, deve ser ressaltado que no "universo trans" 4 há outras figuras que compõem algumas das classificações da identidade de gênero, mas não serão abordadas no presente estudo.

Explanados os conceitos de sexo biológico designado e identidade de gênero, faz-se necessária a abordagem da classificação realizada a partir desses dois dados. Tem-se, então, as seguintes possibilidades: (i) Mulher cisgênero $^{5}$ é a mulher a qual teve o seu sexo biológico designado como feminino, identificando-se com este mesmo sexo no tocante ao gênero, ou seja, indivíduo que nasceu fêmea e se expressa como mulher; (ii) homem cisgênero é o mesmo conceito de mulher cisgênero, porém na esfera masculina, neste caso, o indivíduo nasceu macho e se expressa de forma

\footnotetext{
4 Expressão utilizada por Juliana Gonzada Jayme (2010, 2010, p. 167), referindo-se ao contexto transexual de forma genérica.

5 Cisgênero, cissexual ou cis são pessoas que foram designadas com um gênero ao nascer e se identificam com ele (MDH, p. 10).
} 
masculina; (iii) mulher transgênero 6 é a mulher a qual teve o seu sexo biológico designado como masculino, porém expressa sua identidade de gênero de forma feminina, ou seja, o indivíduo que nasceu macho, mas se expressa de forma feminina; (iv) homem transgênero, de forma contrária, é o indivíduo que nasceu fêmea, mas se expressa de forma masculina.

\subsection{Sexualidade}

Definidos os conceitos de sexo biologicamente designado e identidade de gênero, faz-se necessária a abordagem de uma terceira categoria: A sexualidade. Nesta categoria, assim como na categoria identidade de gênero, há uma ordem heteronormativa ${ }^{7}$, tendente a achar que o gênero e a sexualidade decorrem do sexo biológico.

Entretanto, a sexualidade não é uma regra matemática tão lógica como tratada pela heteronormatividade. A sexualidade se manifesta de forma desvinculada da identidade de gênero, significa dizer que a sexualidade é autônoma, independente, não é uma regra lógica decorrente da identidade de gênero ou do sexo biologicamente designado.

O foco do presente estudo não reside na sexualidade, razão pela qual a abordagem neste tópico se limita a consignar que a sexualidade se manifesta de diversas maneiras, surgindo as figuras da heterosexualidade, homossexualidade, bissexualidade, assexualidade, entre outras.

\section{Garantias trazidas pela lei 11.340/2006}

Advindo a Lei 11.340/2006, as mulheres em situação de violência doméstica e familiar passaram a contar com novas ferramentas introduzidas no Ordenamento Jurídico brasileiro.

6 Transgênero ou trans são pessoas que possuem uma identidade de gênero diferente do sexo designado no nascimento (ABGLT, 2011, p. 17).

7 Expressão utilizada para descrever ou identificar uma suposta norma social relacionada ao comportamento padronizado heterossexual (MDH, p. 05). 
As ferramentas legais criadas pela Lei 11.340 com o intuito de "[...] coibir e prevenir a violência doméstica e familiar contra a mulher [...]" (BRASIL, 2006), expressa um grande passo referente às reivindicações de desconstrução cultural de um padrão feminino e masculino, "envolvendo relações de poder e impondo comportamentos aos homens e às mulheres" (ANGELIN; MADERS, 2010).

Extrai-se, a princípio, que a Lei Maria da Penha "ao prever mecanismos de prevenção, assistência às vítimas, políticas públicas e punição mais rigorosa para o agressor" (CAVALCANTI, 2010, p. 190), revela-se adequada para "atender a complexidade do fenômeno violência doméstica" (CAVALCANTI, 2010, p. 191). Além disso, a LMP trouxe uma expressiva inovação ao definir os modos de violência ao longo de seu artigo $7^{\circ}$, conceituando a violência física, psicológica, sexual, patrimonial e moral.

Infere-se que o escopo principal da LMP não é a implantação de medidas punitivas mais severas e rígidas, trata-se de um texto legal para promoção de conscientização social, conferindo a proteção essencial à mulher em situação de violência doméstica. Criam-se mecanismos que asseguram a assistência mais eficiente às vítimas, implantando a ideia de reprovabilidade da conduta de violência doméstica contra a mulher (CAVALCANTI, 2010, p. 189).

Então, por atender aos objetivos de combate aos atos de violência doméstica, é que problemática do presente estudo ganha forma. O texto normativo confere proteção especial às vítimas mulheres que se encontram em situação de violência doméstica e familiar, porém, exatamente no mesmo contexto o qual a LMP se refere, há as vítimas transmulheres e transexuais. Ante a redação duvidosa da Lei 11.340/2006, o presente trabalho se propõe a verificar a (in)aplicabilidade da Lei Maria da Penha aos casos em que essas mulheres figuram como vítimas de violência doméstica e familiar. 


\section{A tutela da lei 11.340/2006 às transmulheres e travestis em situação de violência doméstica e familiar}

Para a análise da aplicabilidade da Lei Maria da Penha aos casos em que mulheres transexuais e travestis estejam na condição de vítima da violência doméstica e familiar, é preciso aferir o objeto de proteção da Lei 11.340/2006.

Logo no primeiro artigo da LMP, encontra-se o objetivo da Lei e seu objeto: "Esta Lei cria mecanismos para coibir e prevenir a violência doméstica e familiar contra a mulher [...]" (BRASIL, 2006), sinalizando, desde já, de forma inequívoca, que a proteção é conferida à mulher. Entretanto, a expressão "mulher" pode ser empregada em situações distintas. Passa-se à verificação dessas situações.

Em se tratando de sexo biologicamente designado, conforme tratado anteriormente na base teórica deste estudo, o termo "mulher" é empregado como sinônimo de "fêmea", "feminino". Nesta situação, o termo faz referência à classificação recebida pelo indivíduo no ato do seu nascimento, considerando o seu sistema reprodutor, apenas.

O mesmo termo "mulher" é empregado na classificação de identidade de gênero. Exposta ao longo da base teórica do presente estudo, a identidade de gênero faz referência à "[...] conviç̧ão de ser masculino ou feminina, conforme os atributos, comportamentos e papéis convencionalmente estabelecidos para os machos e fêmeas" (SILVA, 2016, p. 19). Em se tratando de identidade de gênero, há as seguintes figuras femininas: A mulher cisgênero, a mulher transgênero e a travesti, fazendo referência à mulher que se identifica com as feminilidades sociais. 
A proteção, então, conferida à mulher, a qual a Lei 11.340/2006 se refere, seria a mulher biologicamente designada ou seria a mulher que assume a feminilidade e se identifica com a identidade de gênero feminina?

\subsection{A vulnerabilidade do sujeito passivo da Lei Maria da Penha}

A proteção tratada na LMP é conferida ao gênero "mulher", consequentemente tem-se que a vulnerabilidade à violência doméstica e familiar é decorrente deste, mas não da classificação biológica "macho/fêmea". Verifica-se que, tanto a mulher cisgênero, quanto a mulher transgênero e a travesti permanecem expostas à vulnerabilidade social em seus lares em razão do gênero feminino vivenciado.

A vulnerabilidade tratada neste estudo faz referência à fragilidade e fraqueza enfrentadas pelo gênero feminino em razão dos aspectos culturais já tratados anteriormente. A fonte para constatação dessa fraqueza, parte da base nacional do Sistema de Informações de Mortalidade - SIM, da Secretaria de Vigilância em Saúde - SVS do Ministério da Saúde - MS, que serviu para a elaboração do Atlas da Violência (2017), utilizando dados do período de 2005 a 2015. Constatou-se, através dos registros efetuados, que neste período de 10 anos, mais de 50 mil mulheres foram assassinadas no Brasil.

Dados da mesma base de dados foram catalogados e formaram o Mapa da Violência (WAISELFISZ, 2015), o qual, utilizando o quantitativo de homicídios de mulheres ocorridos no período de 2003 a 2013, constatou que mais de $27 \%$ dos homicídios de mulheres no referido período ocorreu no próprio lar da vítima.

Resta demonstrado, então, que o ambiente doméstico é um local que oferece risco à integridade física, psicológica e moral das mulheres. Essa margem de risco é traduzida pelas expressões vulnerabilidade e fragilidade. 


\subsubsection{Transmulheres e travestis vulneráveis à violência no ambiente doméstico e familiar}

Os dados trazidos pelo Atlas da Violência e pelo Mapa da Violência evidenciam que a mulher se torna vítima de violência em seu próprio lar. Nota-se, no entanto, que ambas as pesquisas são silentes no tocante às possíveis estatísticas relacionadas às vítimas transmulheres e travestis. Porém, a ausência de estatísticas catalogadas acerca da violência doméstica e familiar praticada contra transmulheres e travestis não expressa a ausência de violência, expressa, na verdade, a necessidade de implementação de políticas públicas para identificar e combater o ato violento de forma ágil e eficaz.

Apesar da deficiência de dados, um estudo publicado pela Revista Gaúcha de Enfermagem, de Porto Alegre, trouxe uma importante noção das estatísticas acerca da violência contra transmulheres e travestis. O levantamento foi realizado no município de Cajazeiras, estado de Paraíba, região Nordeste do Brasil. Os dados foram coletados no ano de 2014, considerando a participação de 13 travestis e 3 transexuais. O estudo revelou que 12 dos 16 entrevistados sofreram algum tipo de violência, sendo 05 deles vítimas de violência praticada por algum membro da própria família (SILVA, 2016).

Embora o monitoramento de violência no país não faça referência específica às mulheres transexuais e travestis, é possível pinçar dados que, ao serem confrontados com pesquisas de livre iniciativa, corroboram a existência de vulnerabilidade à violência doméstica e familiar em que as mulheres transexuais e travestis permanecem expostas, exatamente como ocorre com as mulheres cisgênero. 


\subsection{Evidências da tutela estatal às transmulheres e travestis em situação de violência doméstica com base na Lei 11.340/2006}

Buscando identificar a aplicabilidade da Lei Maria da Penha aos casos em que as vítimas vivam a feminilidade social do gênero feminino, encontra-se sólidos entendimentos sobre o tema. Entre os juristas, destacase a defesa por Maria Berenice Dias (2010, p. 58)

[...] transexuais, travestis [...] que tenham identidade social com o sexo feminino estão ao abrigo da Lei Maria da Penha. A agressão contra ela no âmbito familiar constitui violência doméstica. [...] descabe deixas à margem da proteção legal aqueles que se reconhecem como mulher.

$\mathrm{Na}$ mesma esteira, a Comissão Permanente de Combate à Violência Doméstica e Familiar contra a Mulher - COPEVID, comissão do Conselho Nacional dos Procuradores-Gerais dos Ministérios Públicos dos Estados e da União - CNPG, aprovou o Enunciado 30 (COPEVID, 2016) na reunião de colegiado do CNPG em 15/06/2016, tratando do tema em análise. Conforme dispositivo divulgado:

Enunciado ${ }^{\circ} 30$ (001/2016):

A Lei Maria da Penha pode ser aplicada a mulheres transexuais e/ou travestis, independentemente de cirurgia de transgenitalização, alteração do nome ou sexo no documento civil.

O enunciado está em perfeita harmonia com o conceito de transexualidade, fazendo referencia de forma bastante pontual às mulheres transexuais e às travestis, demonstrando a necessidade de o entendimento ser pacificado entre os operadores do Direito.

Verifica-se, portanto, que a questão acerca da aplicabilidade da Lei 11.340/2006 é algo que ainda diverge. Aliás, a questão é tão controvertida que, atualmente, tramita na Câmera dos Deputados no Congresso Nacional o Projeto de Lei 8.032/2014 de autoria da Deputada Jandira Feghali, propondo a ampliação expressa da proteção conferida às vítimas que 
vivenciam a feminilidade, através de inclusão de parágrafo único ao artigo $5^{\circ}$ da Lei 11.340/2006, contendo a seguinte redação: "As relações pessoais enunciadas neste artigo independem de orientação sexual e se aplicam às pessoas transexuais e transgêneros que se identifiquem como mulheres" (BRASIL, 2014).

Não é duvidosa que a dicotomia "macho/fêmea" não é a melhor forma para nortear a aplicabilidade da Lei Maria da Penha, uma vez que limitar a tutela à mulher cisgênero, é perpetuar a desigualdade e fechar os olhos para a equidade, afrontando a própria dignidade da pessoa humana e os princípios constitucionalmente consolidados no rol de direitos fundamentais da Constituição da República Brasileira de 1988, atualmente vigente.

\section{Considerações finais}

Embora o texto constitucional expresse a igualdade entre homem e mulher, ainda é preocupante o índice de violência doméstica e familiar contra as mulheres. Analisando as estatísticas expostas ao longo do estudo, verificou-se que o ambiente doméstico, infelizmente, é um local onde a mulher se torna vítima de figuras masculinas da família, como o companheiro, namorado, pai, entre outros.

Ante a inércia do Estado brasileiro para julgar o caso Maria da Penha, de repercussão internacional, a Organização dos Estados Americanos - OEA foi acionada, culminando na criação da Lei 11.340/2006, batizada como "Lei Marida da Penha".

A partir de 2006, então, o Ordenamento Jurídico Brasileiro passou a dispor de mecanismo específico de proteção à mulher em situação de violência doméstica e familiar. A problemática tratada no presente estudo analisou a expressão "mulher", visando identificar a possível aplicabilidade 
da Lei Maria da Penha aos casos de violência doméstica e familiar, envolvendo vítimas mulheres transexuais e travestis.

A princípio, o estudo concluiu que a expressão "mulher" é utilizada em duas classificações distintas: (i) Referente ao sexo biologicamente designado, sendo sinônimo da expressão "fêmea"; (ii) utilizada na classificação da identidade de gênero, sendo sinônimo de "feminino".

Concluiu, também, que o sexo biologicamente designado não vincula a identidade de gênero, ou seja, o indivíduo que nasceu com o sexo biologicamente designado "macho" não se identificará, obrigatoriamente, com a identidade de gênero masculina, surgindo, a partir dessa análise, as figuras da transmulher e da travesti, que vivenciam a feminilidade no cotidiano, ainda que tenham nascido num corpo biologicamente "macho". Identidade de gênero é, portanto, independente do sexo biológico.

Com relação ao objeto de proteção, o estudo analisou a Lei 11.340/2006 desde o seu projeto, e concluiu que a proteção é conferida ao gênero mulher em razão de vulnerabilidade permanente em que é exposta em seu próprio lar.

Com relação ao sistema normativo brasileiro, o estudo concluiu que se trata de sistema binário, considerando apenas a existência de dois sexos biológicos, para os quais equivalem apenas dois gêneros distintos: o feminino e o masculino, apenas. Assim, a legislação brasileira toma por regra que toda pessoa biologicamente feminina deva pertencer ao gênero mulher, e vice-versa. Ocorre que, como já demonstrado ao longo do estudo, essa não é a realidade humana e social. A equivalência binária entre sexo biológico e gênero já foi ultrapassada e, apesar de ainda ilustrar o imaginário do legislador, em muitos casos, não corresponde mais às pessoas que o Direito objetiva tutelar. 
Necessário ressaltar que a norma deve atender à realidade social que regula, sob risco de tornar-se inócua ou ser revogada pelo desuso, espera-se que a LMP acompanhe o contexto da feminilidade e do conceito de mulher, que ultrapassa a mera construção binária tradicional.

Assim, em se tratando de proteção ao gênero vulnerável nas relações domésticas, o estudo concluiu que deverão ser protegidas no âmbito da Lei 11.340/2006 as transmulheres e travestis, as quais se identificam e vivenciam o gênero feminino, independente do sexo biológico designado.

Por fim, a instituição familiar, apesar de privada, não é isenta de influência estatal. O Estado pode e deve interferir para desconstruir a cultura de violência intrafamiliar, e tratar como um verdadeiro problema de relevância social, independente do formato de família.

\section{Referências}

ABGLT, Associação Brasileira de Gays, Lésbicas, Bissexuais, Travestis e Transexuais. Manual de comunicação LGBT. 2011. Disponível em: $<$ https://unaids.org.br/wp-content/uploads/2015/09/Manual-deComunica\%C3\%A7\%C3\%A30-LGBT.pdf>. Acesso em: 12 out. 2017.

BIANCHINI, Alice. Lei Maria da Penha: Lei n ${ }^{\circ}$ 11.340/2006: aspectos assistenciais, protetivos e criminais da violência de gênero/Alice Bianchini. 3. ed. São Paulo: Saraiva, 2016. 292 p.

BRASIL, Câmara dos Deputados. Projeto de Lei PL 4.559/2004. Cria mecanismos para coibir a violência doméstica e familiar contra a mulher, nos termos do $\S 8^{\circ}$ do art. 226 da Constituição Federal, e dá outras providências. Transformado em Lei Ordinária 11.340/2006. Disponível em: $<$ http://www.camara.gov.br/proposicoesWeb/fichadetramitacao?idProposicao =272058>. Acesso em: 19 jun. 2017.

BRASIL, Câmara dos Deputados. Projeto de Lei PL 8.032/2014. Amplia a proteção de que trata a Lei 11.340 , de 7 de agosto de 2006 - Lei Maria da Penha - às pessoas transexuais e transgêneros. 2014. Disponível em: $<$ http://www.camara.gov.br/proposicoesWeb/fichadetramitacao?idProposicao $=623761>$. Acesso em: 19 jun. 2017. 
BRASIL. Constituição da República Federativa do Brasil de 1988.

Promulgada em 5 de outubro de 1988. Disponível em:

<http://www.planalto.gov.br/ccivil_03/constituicao/constituicao.htm>. Acesso em: 31 ago. 2017.

BRASIL. Lei $\mathrm{n}^{\circ} 11.340$, de 07 de agosto de 2006. Cria mecanismos para coibir a violência doméstica e familiar contra a mulher, nos termos do 880 do art. 226 da Constituição Federal, da Convenção sobre a Eliminação de Todas as Formas de Discriminação contra as Mulheres e da Convenção Interamericana para Prevenir, Punir e Erradicar a Violência contra a Mulher; dispõe sobre a criação dos Juizados de Violência Doméstica e Familiar contra a Mulher; altera o Código de Processo Penal, o Código Penal e a Lei de Execução Penal; e dá outras providências. 2006.

Disponível em: <http://www.planalto.gov.br/ccivil 03/ ato20042006/2006/lei/111340.htm>. Acesso em: 15 set. 2017.

CANEDO, Daniele. “Cultura é o quê?”- reflexões sobre o conceito de cultura e a atuação dos poderes públicos. In: V ENECULT - ENCONTRO DE ESTUDOS MULTIDISCIPLINARES EM CULTURA. 27 a 29 de maio de 2009. Faculdade de Comunicação/UFBa, Salvador/Bahia. Disponível em: <http://www.cult.ufba.br/enecult2009/19353.pdf>. Acesso em: 31 ago. 2017.

CAVALCANTI, Stela Valéria Soares de Farias. Violência Doméstica: Análise da Lei "Maria da Penha", N 11.340/2006. 3. ed. Salvador: Juspodivm, 2010.

CHAUÍ, Marilena. Repressão sexual, essa nossa (des)conhecida. 12. ed. São Paulo: Brasiliense, 1984, p. 117 apud CAVALCANTI, Stela Valéria Soares de Farias. Violência Doméstica: Análise da Lei "Maria da Penha", N $11.340 / 2006$.

CIDH - Comissão Interamericana de Direitos Humanos. Relatório $n^{\circ}$ 54/01: Caso 12.051. 2001. Disponível em:

<http://www.sbdp.org.br/arquivos/material/299 Relat\%20n.pdf>. Acesso em: 20 mar. 2018.

CNPG - Conselho Nacional dos Procuradores-Gerais de Justiça dos Ministérios Públicos dos Estados e da União. O enfrentamento à violência doméstica e familiar contra a mulher: Uma construção coletiva. 2011. Disponível em:

<https://transparencia.mpmt.mp.br/source/campanhas/7.pdf > . Acesso em: 03 nov. 2017.

COPEVID, Comissão Permanente de Combate à Violência Doméstica e Familiar contra a Mulher - COPEVID. Enunciados COPEVID. 2016. Disponível em: < https://www.mpes.mp.br/Arquivos/Anexos/2554e2b5-456f4554-a0af-d700e58652cb.docx>. Acesso em: 03 Nov. 2017. 
DIAS, Maria Berenice. A Lei Maria da Penha na Justiça: A efetividade da Lei 11.340/2006 de combate à violência doméstica e familiar contra a mulher. 2. ed. São Paulo: Revista dos Tribunais, 2010.

FERREIRA, Aurélio Buarque de Holanda. Miniaurélio Século XXI: o minidicionário da língua portuguesa. 4 ed, Rio de Janeiro, Nova Fronteira, 2001.

FUNDAÇÃO PERSEU ABRAMO, 2001, apud BRASIL, Câmara dos Deputados. Projeto de Lei PL 4.559/2004. Cria mecanismos para coibir a violência doméstica e familiar contra a mulher. Transformado em Lei Ordinária11.340/2006. Disponível em:

<http://www.camara.gov.br/proposicoesWeb/fichadetramitacao?idProposicao $=272058>$. Acesso em: 19 jun. 2017.

JAYME, Juliana Gonzaga. Travestis, transformistas, drag queens, transexuais: montando corpo, pessoa, identidade e gênero. Cultura contemporânea, identidades e sociabilidades: olhares sobre corpo, mídia e novas tecnologias. São Paulo: UNESP: São Paulo: Cultura Acadêmica, 2010. Disponível em: <http://books.scielo.org/id/js9g6/pdf/castro-978857983095208.pdf>. Acesso: 15 out. 2017.

JESUS, Jaqueline Gomes de. Orientações sobre identidade de gênero: conceitos e termos. Brasília, 2012. Disponível em:<http://www.diversidadesexual.com.br/wpcontent/uploads/2013/04/G\%C3\%8ANERO-CONCEITOS-E-TERMOS.pdf>. Acesso em: 12 nov. 2017.

KRUG, Etiene G., et al. Relatório Mundial Sobre Violência e Saúde. Organização Munidial da Saúde. Disponível em: https://www.opas.org.br/wp-content/uploads/2015/09/relatorio-mundialviolencia-saude.pdf. Acesso em: 04 nov. 2017.

ANGELIN, Rosangela; MADERS, Angelita Maria. A construção da equidade nas relações de gênero e o movimento feminista no Brasil: avanços e desafios. Cadernos de Direito, Piracicaba/SP, v. 10, n. 19, 2010. DOI:< http://dx.doi.org/10.15600/2238-1228/cd.v10n19p91-115. Disponível em: https://www.metodista.br/revistas/revistasunimep/index.php/cd/article/view/232/4\%2009>. Acesso em: 20 out. 2017.

WAISELFISZ, Julio Jacobo. Mapa da Violência 2015: Homicídio de mulheres no Brasil. $1^{a}$ Ed. Brasília/DF, 2015. Disponível em: <http://www.mapadaviolencia.org.br/pdf2015/MapaViolencia_2015_mulhere s.pdf>. Acesso em: 21 mar. 2018. MDH, Ministério dos Direitos Humanos. Glossário específico: População LGBT. Disponível em: <http://www.sdh.gov.br/assuntos/conferenciasdh/3aconferencia-nacional-lgbt/conceitos/glossario-lgbt>. Acesso em: 15 out. 2017. 
NARVAZ, Martha Giudice. Submissão e resistência: Explodindo o discurso patriarcal da dominação feminina. Programa de Pós-graduação em Psicologia do Desenvolvimento, Universidade Federal do Rio Grande do Sul, Porto Alegre/RS. 2005. Disponível em: < http://hdl.handle.net/10183/5442>. Acesso em: 31 ago. 2017.

OEA, Organização dos Estados Americanos. Convenção Americana Sobre Direitos Humanos, de 22 de novembro de 1969. San Jose, Costa Rica. Disponível em:

$<$ https://www.cidh.oas.org/basicos/portugues/c.convencao_americana.htm>. Acesso em: 25 set. 2017.

SILVA, Cristiane Gonçalves da. Orientação sexual, identidades sexuais e identidade de gênero. 2016. Disponível em:

$<$ http://repositorio.unifesp.br/handle/11600/39169>. Acesso em: 28 out. 2017.

SILVA, Glauber Weder dos Santos et al . Situaçôes de violência contra travestis e transexuais em um município do nordeste brasileiro. Revista Gaúcha de Enfermagem. Porto Alegre, v. 37, n. 2, e56407, 2016. Disponível em: <http://www.scielo.br/scielo.php?script=sci_arttext\&pid=S198314472016000200404\&lng=pt\&nrm=iso >. Acesso em: 02 nov. 2017.

TEDXFORTALEZA. Maria da Penha: Uma história de vida!. Fortaleza: TedxTalks, 2012. Disponível em:

$<$ https://www.youtube.com/watch?v=TRSfTdaBbvs $>$. Acesso em: 24 set. 2017.

Recebido em março de 2018. Aprovado em novembro de 2018. 